\title{
Why language is not Enough - Work-Based Learning in Global Organisations
}

\section{Introduction}

For many larger organisations, increased globalization means that employees, collaborators and customers are distributed throughout the world. This requires a focus within the organisation on the continuing competence development of people from all three groups, in order to make it possible for them to perform competently in their daily work. Many global organisations such as Danfoss A/S and Danske Bank have chosen to utilize live on-line communication and learning platforms in their competence development courses. Such platforms present several different audiovisual communication possibilities. A typical example is Interwise[1] (see figure 1) which is utilized by both Danfoss $A / S$ and Danske Bank[2]. 


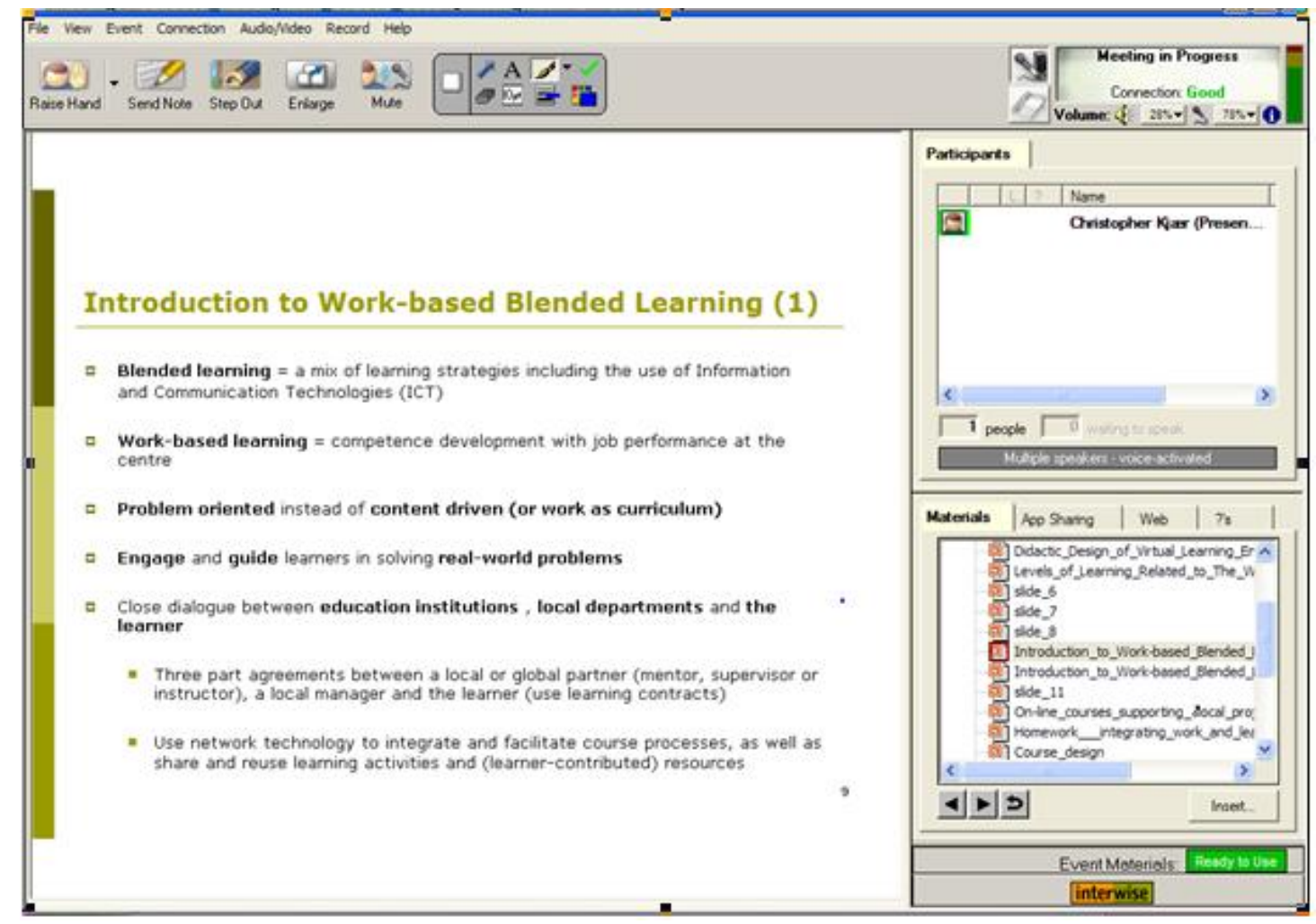

Figure 1. Screen shot of the Interwise learning and communication platform

In practice, courses utilizing such on-line communication systems are often conducted as a series of virtual lessons in which instructors present 'course material' orally with the aid of PowerPoint slides, allowing learners to interrupt with questions and perhaps leaving some time for discussion between participants towards the end of a lesson[3]. Such teaching practice builds upon an implicit conception of knowledge as linguistically expressible information, which can be acquired in one setting through 'information-transfer' from instructor to learner, and then be transferred and used in another setting without any major problems.

However, if the overall objective of a course is that the participants develop their competence in relation to their daily work, one needs to take a perspective on knowledge and learning that goes beyond the conception which these kinds of systems support.

In this article we are going to argue for a different concept of knowledge and learning: The 'knowledge in practice' of the competent employee is seen as a unity of linguistically expressible and tacit (experiential and practical) aspects; a unity which cannot be acquired solely through participating in formal course settings. 
The aim of the article is to discuss the didactical implications of our alternative view of knowledge for design of work-based blended learning in global organisations. To focus the discussion of knowledge and learning, we shall begin with presenting an example, which was developed within the context of a case study conducted at the Danish company Danfoss Refrigeration \& Air Condition Academy (Danfoss RA Web Academy). Following the case study will be three theoretical sections, which, with the focus of the case, will elaborate on the issues of 'knowledge in practice', communicating about 'knowledge in practice', and the didactical implications. The article concludes with a summary of the main results presented in a bulleted list.

\section{Case: Designing on-line courses for supporting local project work}

The case study presented here was conducted at Danfoss RA Web Academy[4] and concerned a course on frequency converters for saving energy in cooling systems.

The course was targeted at sales technicians and had two main subject areas: the technical features of the converters, including their benefits in saving energy with respect to larger cooling systems; and the sales of these converters. The Web Academy is a virtual platform on which Danfoss employees worldwide can sign up for different kinds of on-line courses using the system Interwise mentioned above. Framed by these conditions, a course was designed which sought to integrate synchronous on-line sessions with local project work made by the participants. The structure of the course was inspired by the principles of problem-oriented project pedagogy (Illeris 2004, Dirckinck-Holmfeld 2002), which emphasises the importance of problem orientation and participant direction. The problem orientation supports the participants in developing a capability of identifying and delimiting problems of relevance (to the employee, to the customer, and/or to the company) in a given situation as well as competence in dealing with and solving such problems. The development of these competences is further advanced by the principle of participant direction, which in addition aims at heightening the motivation of the participants by letting them direct their learning as much as possible in the given circumstances.

In the course, the participants not only work with predefined problems, but also with examples of authentic work problems which they found meaningful in relation to their actual jobs. In this way, 
the principles of problem orientation and participant direction were invoked to increase the possibilities experienced by the sales technicians of situating the on-line course in their own workplace realities. The data from the case study suggest that this had a motivating influence on the learning and competence development of the participants.

The structure of the course was as follows:

It consists of a series of six live on-line sessions on the virtual learning and communications system (one session per week), in combination with homework in the form of the parallel project work. The live on-line sessions were to provide the participants with both relevant information about products and feedback on the local project work. The participants were working in local project groups two and two.

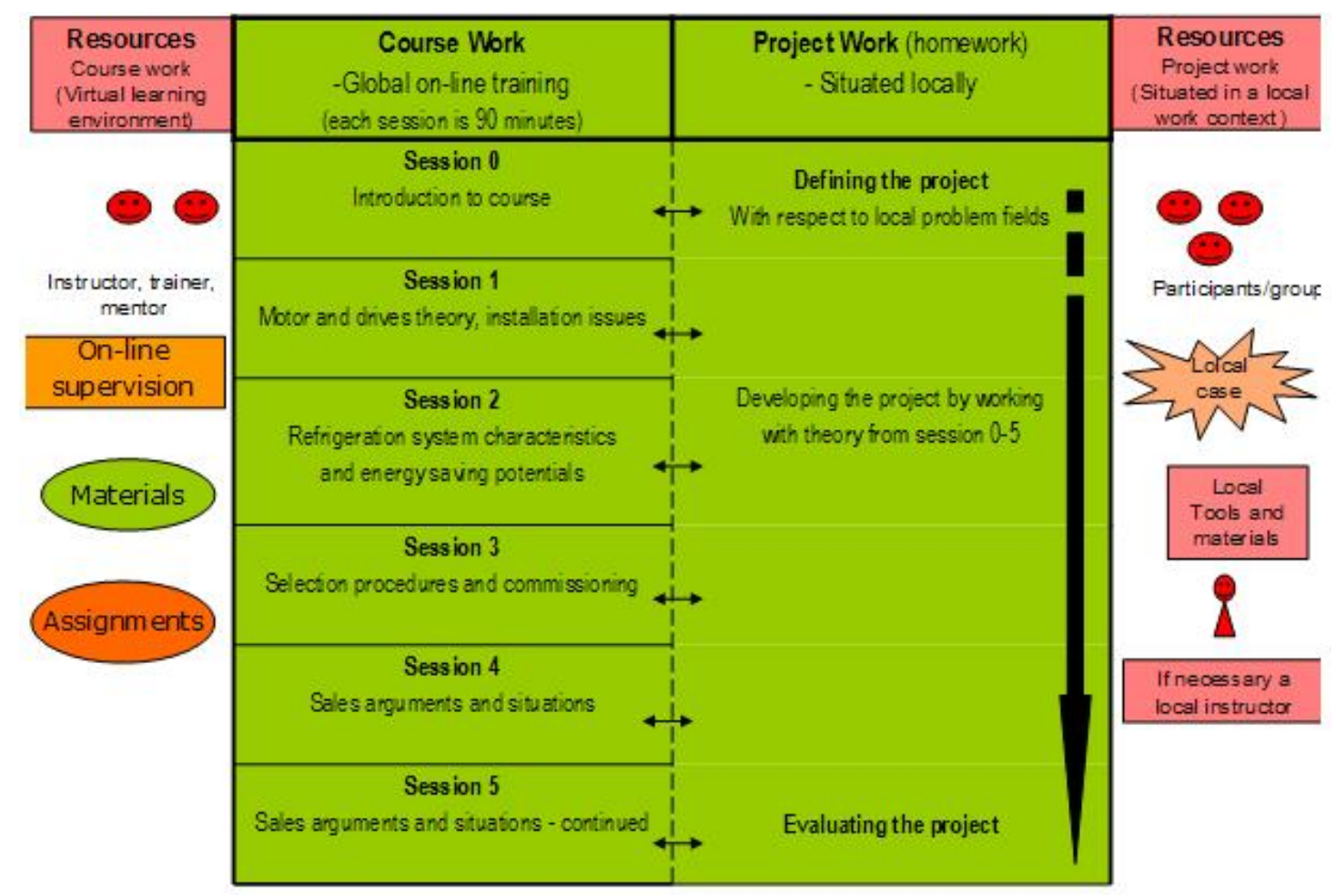

Figure 2. The structure and content of the course. Adapted from Dirckinck-Holmfeld (2002).

As represented in figure 2, the primary subject of each on-line session was relevant expert knowledge about frequency converters. However, time was also allocated to discussion to facilitate collective reflection on the local projects of the participants. 
In practice, each on-line session began with a short discussion of questions and experiences presented by the participants. Subsequently followed a more traditional on-line lecture.

The most important phase in the project work was the first step, where the participants had to identify a relevant authentic workbased problem as focal point for their project activities. The requirements posed for the work-based problem were that it had to 1) arise from the work of the participants, 2) be experienced as meaningful by them, and 3) be within the given course frame.

Since the main objective of the course was to support sales technicians in their learning of frequency converters and the sales hereof, the overall frame for the project work was - step by step to develop a personalized product presentation, attuned to the local context and the specific job tasks of the participant in question. To support the participants in their work with the different steps of the project, the instructors supplied continuous feedback via a discussion forum on the Web Academy. Further, the course was designed in such a way that there was a strong thematic correlation between each on-line session and the current stage of the project: At each stage, the expert knowledge concerning specific product features and the sales of frequency converters necessary for the next phase of the project work would be given just before this phase was entered. As an additional support, each on-line session was recorded and saved. This allowed all participants to revisit the sessions, including the PowerPoint slides and the oral communication. This possibility was used by all participants.

Methodologically, the case study was conducted as classroom observation and qualitative research interviews with the course participants. The data collected provided evidence that four different virtual and local learning arenas were important in the learning processes of the participants (Kjær, in prep.). 


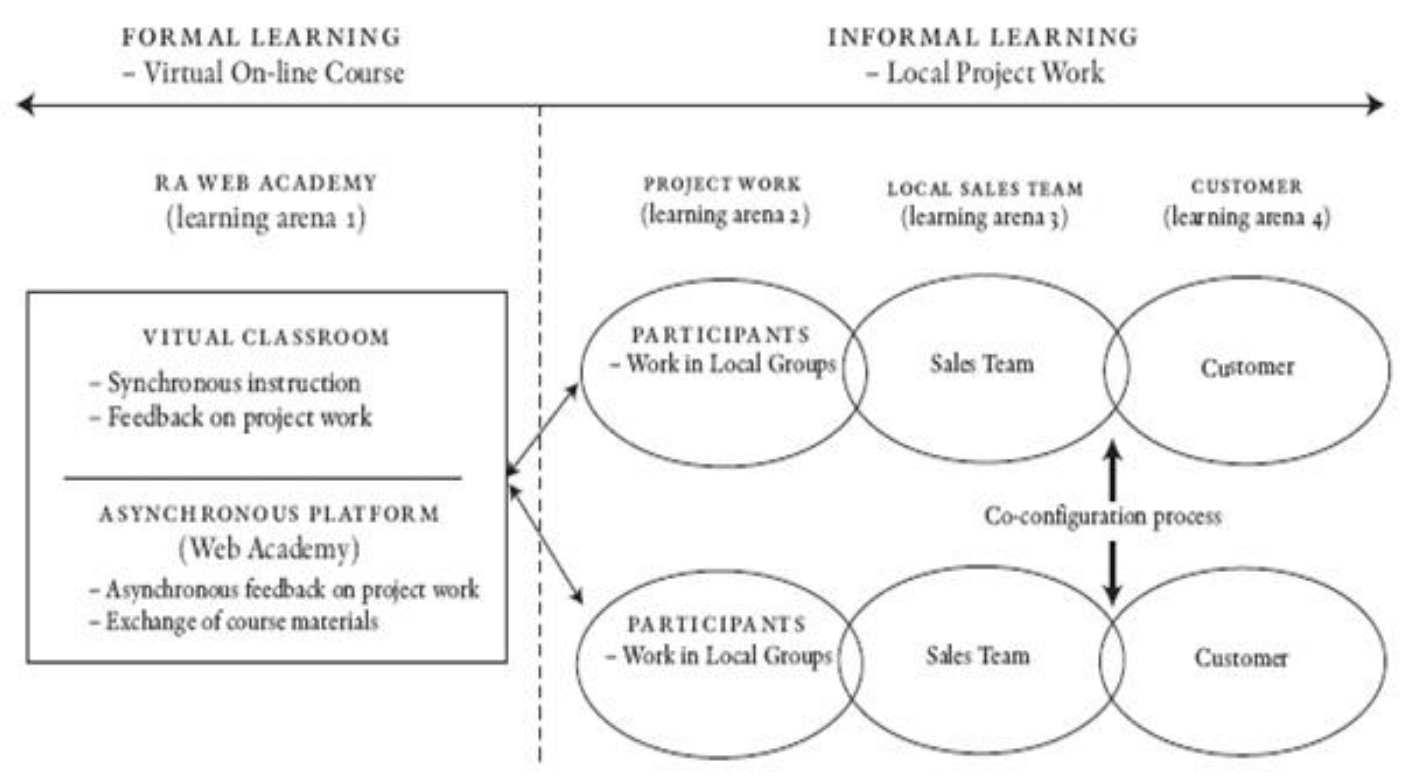

Figure 3: Learning arenas in the Danfoss case

Looking at figure 3, the left side of the dotted line, learning arena 1 , depicts the formalized learning environment consisting of the synchronous on-line sessions in the virtual classroom and the asynchronous feedback on the project work. In this specific learning arena, the main goal was to provide course participants with the relevant knowledge. The focus here was on the chosen course curriculum and on the instructor as the expert.

On the right side of the dotted line, the circles depict the work of the course participants in their local project groups (arena 2), in their sales teams within their respective departments (arena 3), and finally in their negotiations with their customers (arena 4). The learning activities and learning processes taking place here are of a more informal kind because they come about as integral parts of the authentic work tasks of the participants, instead of being deliberately constructed by the course instructor. Their occurrence is, of course, to some extent indirectly designed for the overall project work frame of the course, but the learning situations themselves are 'out of reach' of the instructor. As described in more detail in the following sections, there are several advantages in combining the principles of problem-oriented project pedagogy with more traditional on-line courses. First and foremost, personal experiences and practical knowledge gained from working with the local project make up an important background, which gives meaning to the explicit (linguistically expressed) knowledge presented in the global formalized on-line sessions.

Secondly, the global on-line part of the course on the other hand allows a joint reflection to evolve on the local projects and their 
settings - a reflection, which involves both experts and course participants[5].

In short, the learning activities of the participant consists of combinations of global web-based activities and the participation in local physical work settings. Through the latter, the course participants build up authentic work experiences centred around working with frequency converters in sales situations. These experiences are then discussed and reflected, practically and theoretically, in the different learning arenas. For this reason, the learning of the participants is best viewed as taking place not only in the different arenas, but as much in the traversing of the arenas by the participant. As elaborated in more detail below, this has important consequences for the learning and competence development of the participants.

\section{Knowledge as 'knowledge in practice'}

In this article, the 'knowledge in practice' of the practitioner is viewed as involving three aspects. These aspects are interdependent, but can be distinguished analytically as

1) Linguistically expressible knowledge ('know that'),

2) Practical knowledge ('know how'/skill),

3) Personal experience ('know of')[6].

The first, 'know that', is 'what you can say', e.g. "Eastern Japan has an AC frequency of $50 \mathrm{~Hz}$, whereas Western Japan has an AC frequency of $60 \mathrm{~Hz}$ "; "Canberra is the capitol of Australia" and "In Japan, you take off your shoes before entering a person's home". The second, 'know how', is 'what you can do', e.g. the skill of mounting a frequency converter, of using the functionalities of an ICT system in communication, and of being able to fine-tune one's choice of words and tone of voice to the mood of one's conversation partner.

The third, 'know of', is 'what you have experienced yourself'. It ranges from relatively simple examples like knowing what the colour 'mauve' or a frequency converter looks like, to more complex 'life experiences' like 'knowing what it feels like to lose an order you have been working to get for half a year'.

The three aspects mutually acquire meaning from each other: When you understand linguistically expressible knowledge, you draw on 
the practical knowledge and personal experience you have, to make the words get a fuller meaning than they have on their own. On the other hand, the linguistically expressible knowledge supplies structure to the practical and experiential aspects. This makes it possible to further interpret, to redirect, and to transform them.

The three aspects are not different forms of knowledge existing independently of each other and combined to make up a synthesis. Instead, they form a holistic unity, the 'knowledge in practice' of the practitioner. This unity is an action-oriented perspective on the situation which allows relevant aspects to present themselves as 'to be acted upon'. 'Knowledge in practice' is a perspective with which the agent meets the world and through which the world makes sense to him.

Given this view of knowledge, what can be said about the 'knowledge in practice' of the sales technicians in the Danfoss case? What must a sales technician know to master the negotiation process of selling a product like the frequency converter[7]? Knowledge is required within a range of fields, including

the technical features of the frequency converter and the possibilities of its customization;

-the culture and organisation of the customer;

-how to adjust to different personalities;

-sales technique and 'sales tricks';

-typical problems met in practice when introducing the converter. Such problems can be economical, technical, and/or organisational.

In all fields, the knowledge required will be a mix of the three aspects 'know that', 'know how' and 'know of'. For instance, when considering the technical specifications concerning customization, the sales technician draws upon his/her experience and practice to get a fuller understanding of what is actually possible in the concrete situation. She/he will, among other things, draw upon personal experience with how electrical installations in the country in question are set up and how certain customization strategies can lead to break-downs of the system. Likewise, she/he will draw upon practical knowledge of how such break-downs can be overcome, and in a way that is economically and technically feasible. Similarly, when the sales technician is initiating negotiations with a potential customer, she/he will have explicit knowledge of sales technique and of the culture of the customer. In addition this explicit knowledge will acquire specific meaning for the sales technician 
from the 'know of' and 'know how' acquired through her/his former sales.

This description might indicate that the 'knowledge in practice' of the sales technician is split into different areas, corresponding to the bulleted points above. This is not the case. Instead, the 'knowledge in practice' is a unified whole, which in each situation is actualised as a concrete structuring of the situation. In this structuring, all involved areas present themselves with the relevance they have in relation to each other and to the situation as such. This is the sense in which the sales technician's 'knowledge in practice' acts as a perspective: It allows the situation to present itself 'to be acted upon' in a way that is immediately technically, socially, culturally and organisationally adequate. It lets the knowledge itself actualise for the sales technician in each situation in a way that is structured by the situation itself. This means that the technical expertise, sales know how, cultural experience etc. take concrete form by the demands and possibilities of the situation.

It is precisely one of the strengths of the didactic design presented in the Danfoss case that it allows the participants to articulate the linguistically expressible knowledge of the course in relation to the concrete local work problems of the projects. This facilitates an integrated development of both the tacit and the explicit dimensions of knowledge.

\section{Communicating about 'knowledge in practice'}

This view of 'knowledge in practice' stresses the semantic role of tacit knowledge in understanding linguistically expressible knowledge. An obvious question therefore arises: What is involved in communication about knowledge? Or, in a stronger formulation: Is communication about 'knowledge in practice' possible at all, and if so, how?

The answer to these questions in our view is that when we communicate with others, the tacit background of our personal experiences and practical knowledge gives the words uttered by the others a depth and fullness not present in the words taken by themselves. This is so from the banal example of words denoting sensory qualities like 'the sound of an obo' to examples of complex, many-faceted areas of great personal importance like living through a divorce or learning to cope with a diagnosis of fatal illness. More relevant in this connection, when one sales technician talks about his sales presentation with another, both will be drawing upon their personal experience and practical knowledge in their understanding 
of the presentation as a concrete solution to a complex sales problem in a specific cultural, organisational business-related setting.

Furthermore, an actual conversation will have different form and linguistic content, depending on whether or not the conversation partners have - and allow - similar tacit semantic content to give meaning to what the other person is saying. This is so, because the tacit dimensions are part of the perspective of 'knowledge in practice', and because the perspective structures the relevance in the situation. Therefore, without the tacit dimensions, different things will be said.

This difference is experienced in practice as the difference between 'deep' and 'shallow' conversations: The lack of personal experience within the domain talked about shows up as a very superficial understanding of this domain. This superficial understanding in turn will show itself to rely heavily on the reproduction of what others have said rather than on the 'bringing into play' of new meaning to which the person is committed. For the same reason, explaining a professional point to a non-professional can be near-impossible, no matter how many words are used, because the non-professional simply does not have the experience and practical knowledge to 'make sense of the words'. On the other hand, when conversation partners both have an extensive tacit background to draw upon, subtle and deep points (not understandable to an outsider) can often be expressed between them with very few words indeed. From this point of view, the purpose of providing opportunities for 'joint reflection' about the local projects in the Danfoss case is precisely to make possible such 'meaning rich' conversations between course participants, enabling them to 'share experiences'(as the expression goes) and thereby qualify their work.

At this point, a possible objection presents itself: If tacit dimensions of experience and 'know how' are an essential part of our 'deep' understanding of the utterances of others and in particular of explicitly formulated knowledge, how can we 'share experiences' at all? Are we not forced to the opposite conclusion that each of us connects a different meaning with the same words? And that any impression we may have of having had 'deep' conversations is an illusion; that the best we can ever hope for - and what we should aim at - is the 'superficial' understanding at the common linguistic level? That, however, is not necessarily the case: 'Deep' conversations require us to have a sufficient degree of similar tacit knowledge to draw upon; they do not require us to have identical experience and 'know how'. Often we can make ourselves 
understood by relating to like experiences, even if we cannot 'put the experiences themselves into words': To the person who does not know the sound of an obo we might say that it sounds 'something like a duck'. When we do so, we are drawing on the tacit semantic content of these 'like experiences' (the quack of the duck) - we are not doing without the tacit dimensions altogether. For the person born deaf the explication gives no new meaning to the phrase 'sound of an obo'.

It should be stressed that a 'sufficient degree of similar tacit knowledge' cannot be identified once and for all. It will depend on the subject matter itself and its relation with other subject matters and most probably it will depend on the situation and the person involved: Some people simply seem better than others at 'extrapolating' from their own experiences to those of their fellow men. What is important is, firstly, that for each person there is a (personal, situational specific) limit to what she/he can understand without experience and 'know how' within the field, and secondly, that, in general, the more alike our tacit background is, the better we understand each other.

In summary, language is not enough when one wants to communicate adequately about 'knowledge in practice'. This is only possible to the extent that the conversation partners have a sufficiently similar tacit background to draw upon in their conversation. When they have this, they can use language to focus on central aspects of their 'knowledge in practice', reflecting on likenesses and differences in how they see and act in certain situations. This way language can be used to structure and further interpret as well as to question the experiential and practical aspects of 'knowledge in practice', with the aim of further improving the practitioner's competence in practice.

\section{Didactical implications for competence development in global organisations}

The goal of competence development in an organisational setting is the practitioner's improvement of his/her actions in practice.

If one accepts the view of knowledge presented here, the guiding questions for training managers or instructors responsible for the design of competence development should be:

-How does one best facilitate the practitioner's improvement of his/her 'knowledge in practice'? 
-How does one at once support the participants in drawing upon and widening their locally situated experiential and practical meaning and supply the opportunities for them to reflect upon and perhaps question the very local practices which give rise to this tacit meaning?

-How can such 'opportunities for reflecting' be designed in the context of global organisations in a way that takes due account of the fact that the organisation is a global one?

The traditional 'stand-alone' course on e.g. 'sales technique' run by instructors situated in company headquarters, does not constitute an adequate answer to these questions. Such a course focuses on supplying participants with linguistically expressed knowledge, perhaps supplemented by small-scale exercises, which do not possess the inter-related details and commitments of real life situations. It treats knowledge as an object which can be obtained in one context and be transferred to and implemented in another without major loss or transformation. It therefore misses the point that the 'knowledge in practice' to be developed is a situated one and that the practitioner needs locally situated, tacit meaning to make 'meaning rich' sense of the linguistic knowledge. In consequence, such courses - including the exercises - are often experienced as rather 'peripheral' and 'hard to translate into one's own practice'[8].

This 'transfer problem' only becomes bigger when courses are held on a global scale within a world-wide organisation: Local cultural and organisational circumstances may be very different amongst different branches of the organisation, and this will widen the gap between the experiential and practical aspects of the knowledge of the individual participants, both in relation to the instructor and between themselves[9]. These gaps will make it harder for the participants to bring their tacit dimensions into play with and develop them through acquaintance with the course content. It is an important didactical implication of the view of knowledge presented here that competence development must always be anchored in local authentic settings to maximize the chances of a successful outcome.

In designing alternatives to the traditional 'stand-alone' course, the variations in tacit background across a global organisation do not only present a challenge. They also present an opportunity. This is so, because they in principle make possible a meaning rich, yet practice questioning reflection between employees from different local branches. Since the employees work within the same field though in different local settings, the experiential and practical aspects of their knowledge will be similar in many respects, despite 
the variations and gaps in others. This means that the variations and the associated differences in their 'knowledge in practice'perspective can potentially be invoked to challenge local ways of acting and thinking in a reflective dialogue that is meaning rich for all participants. On the other hand, of course, the variations in tacit background present a challenge. It is very demanding both in terms of time and of personal involvement on the part of the participants to establish such a reflective dialogue. Sometimes, their tacit backgrounds may be so disparate that rich communication in practice becomes impossible. The risk of not succeeding is big. There is no easy solution to this problem, but it must be taken into consideration when designing 'opportunities for reflection'. At the very least, the necessary time and space must be provided and the involvement of the participants be encouraged both personally and organisationally, if the meaning rich reflection is to have a chance of succeeding.

The question of commonality across a global organisation is also of great importance when designing an alternative to the 'stand-alone' course. A global organisation is of course in need of a degree of commonality across the local settings for it to present itself as a credible, not too fragmented, organisation. The definition of this 'commonality' to a large extent originates from one local setting, namely company headquarters. But it does not easily translate from headquarters to local branches. It will always be locally mediated, if incorporated at all. This is in part a consequence of the points argued in this article: Because 'language is not enough', headquarters cannot just say how they want the commonality to be. Even the most compliant of local practitioners must necessarily supply local meaning to the words in order for them to make sense for him/her in practice. This is one of the problems that the alternative should be designed to address.

The didactical implications of the view of 'knowledge in practice' presented here are that an adequate competence development programme must provide practitioners with both authentic local and reflective global learning settings. And even more important, the programme must facilitate the movement (both literally and metaphorically speaking) of the practitioners across these settings. The overall focus should be on supporting the participants in their integration of explicit and tacit (practical and experiential) knowledge aspects in relation to the local settings where their 'knowledge in practice' is exercised.

This is not simple to realise in practice, but the didactic model sketched in the Danfoss case supplies a concrete instance of competence development along these lines: The project work of the 
participants provides the local anchoring of the linguistically expressed technical and sales-related knowledge presented in the course. The ICT sessions on the other hand supply the global setting for the participants' communication about and reflection on the locally produced meaning of their project work experiences.

\section{Conclusion}

By way of concluding the article, we wish to summarise our main points. For the sake of clarity we have arranged them in a bulleted list. The main argument has been the following:

'Knowledge in practice' is a unity of linguistically expressible knowledge, practical knowledge and personal experience. The latter two constitute a tacit semantic background for the linguistic knowledge. And this in turn supplies focal points to the tacit dimensions.

When communicating about 'knowledge in practice', one's tacit background gives a fuller meaning to the words of the conversation partner.

Therefore, people who have sufficiently similar tacit backgrounds can have 'deep' 'meaning rich' conversations.

On the basis of this argument, some didactical implications for the design of competence development in global organisations have been presented:

Competence development concerns improving the 'knowledge in practice' of the practitioner.

The design for learning must focus on supporting the practitioner in developing both tacit and explicit aspects of knowledge. It must support the integrated development of these aspects.

For competence development to succeed, global communication about course content must draw on the participant's existing and emerging local experiential and practical meaning.

On the other hand, global communication about local meaning may facilitate critical and transformative reflection upon the local practices.

In general, understanding and reflection is facilitated by the participation in and the transversing of different learning arenas. 
In conclusion, when designing competence development courses, language is not enough, because the tacit dimensions of the knowledge of the participants must actively be brought into play with the linguistically expressible knowledge of the course. This is necessary, if the linguistically expressible knowledge is to have any importance in the continuing work practice of the practitioners. Put differently, the experience and know how of the participants must be brought into the formal settings (IT-based or physical) of the course, for the words to be able to come out of them.

Finally, the Danfoss case supplies one concrete example of how these requirements can be met in practice. It does so, firstly, because of its focus on problem orientation and participant direction. And secondly, because of its integration of local project work with the global IT-based course content.

\section{Authors}

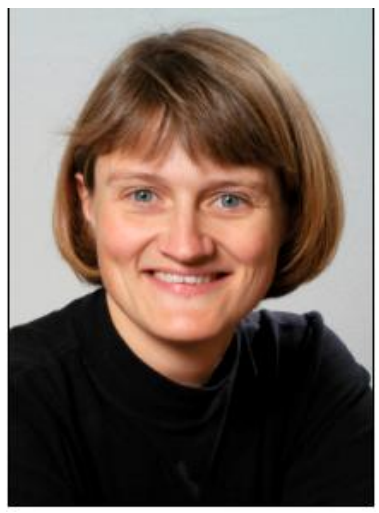

Nina Bonderup Dohn is an associate professor at th University of Southern Denmark.

Nina Bonderup Dohn has as her main research interes the relations between tacit and explicit knowledge, focusing on the role of the body in learning and action

Currently these interests are being applied within the field of computer supported collaborative learning to questions concerning the role of tacit knowledge in networked learning environments.

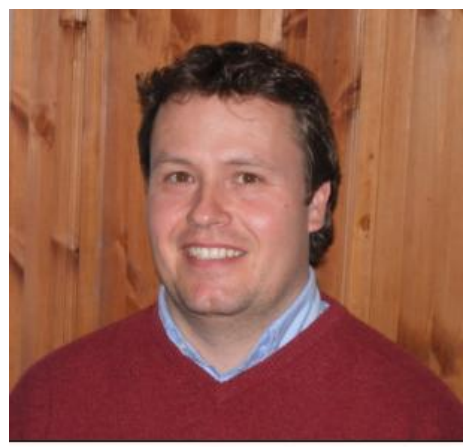

Christopher Kjær owns WBL Consult where he work: as a consultant within the area of learning and competence development in global organizations.

At the same time, he is finishing his $\mathrm{Ph} . \mathrm{d}$ project with the title Work-based Learning in Global Organizations - global online sessions as support for local project wo 


\section{References}

Andersen, Anette/Frederiksen, Birte/Rasmussen, Palle 1996:

Pædagogik og kompetenceudvikling i vaskeriassistentuddannelsen. LEO Arbejdspapir nr. 9. Aalborg: Aalborg University.

Dirckinck-Holmfeld, Lone 2002: Designing Virtual Learning Environments Based on Problem Oriented Project Pedagogy. In Dirckinck-Holmfeld, Lone/Fibiger, B. (eds.), Learning in Virtual Environment. København: Samfundslitteratur, 31-54.

Dohn, Nina B. 2000: Viden i praksis. In Tidsskrift for Socialpædagogik 6, 19-36.

Dohn, Nina B. 2005: Læring i praksis - fremstruktureringen af et handlingsorienteret perspektiv. Aalborg: Aalborg Universitet. Available at:

http://www.learning.aau.dk/dk/forskning/publikationer/phdafhandlinger.htm.

Illeris, Knud 2004: Adult Education and Adult Learning. Roskilde: Roskilde University Press.

Jacobsen, Brian 2003: Samarbejde i synkron Web-baseret undervisning - en undersøgelse af kommunikationsformer og videnstyper i liveevents på Danfoss.Købenahvn: IT-Højskolen (Master Thesis).

Kjær, Christopher, in prep: Arbejdspladsrelateret læring i globale organisationer - globale on-line sessioner som støtte for lokalt projektarbejde. Ph.D. Thesis

Svensson, Lennart/Ellström, Per-Erik/Åberg, Carina 2004: Integrating formal and informal learning at work. In The Journal of Workplace Learning 16/8, 479-491.

Aarkrog, Vibe 2003: Mellem skole og praktik. Fire teoretiske forståelsesrammer til belysning af sammenhængen mellem skole og praktik i erhvervsuddannelserne, København: DPUs Forlag.

This article was uploaded to http://www.languageatwork.eu in July of 2009 and published under a "Creative Commons license Attribution Non-commercial (by-nc)" for more information please go to: http://creativecommons.org/about/license/ 